\title{
Novos registros de Sphaenorhynchus canga (Amphibia, Anura, Hylidae) no Quadrilátero Ferrífero em Minas Gerais, Sudeste do Brasil
}

\section{New records of Sphaenorhynchus canga (Amphibia, Anura, Hylidae) in the Quadrilátero Ferrífero in Minas Gerais, Southeastern Brazil}

\author{
Adriano Lima Silveira ${ }^{1}$, Lucas Soares Vilas Boas Ribeiro ${ }^{2}$, \\ Tiago Teixeira Dornas ${ }^{2}$, Taís Nogueira Fernandes ${ }^{3}$
}

1 Biótica Estudos Ambientais, Caixa Postal 2020, CEP 30270-970, Belo Horizonte, Minas Gerais, Brazil

2 Amplo Engenharia e Gestão de Projetos Ltda., Rua Engenheiro Carlos Antonini 37, São Lucas, CEP 30240-280, Belo Horizonte, Minas Gerais, Brazil

3 Vale S. A., Mina de Águas Claras, prédio 1, térreo, Avenida Doutor Marco Paulo Simon Jardim, CEP 34006-200, Nova Lima, Minas Gerais, Brazil

Corresponding author: Adriano Lima Silveira (biosilveira@yahoo.com.br)

Academic editor: A. M. Leal-Zanchet | Received 4December 2018 | Accepted 30 June 2019 | Published 6February 2020

Citation: Silveira AL, Ribeiro LSVB, Dornas TT, Fernandes TN (2020) Novos registros de Sphaenorhynchus canga (Amphibia, Anura, Hylidae) no Quadrilátero Ferrífero em Minas Gerais, Sudeste do Brasil. Neotropical Biology and Conservation 15(1): 19-28. https://doi.org/10.3897/neotropical.15.e48718

\section{Resumo}

A perereca Sphaenorhynchus canga foi recentemente descrita, com distribuição geográfica restrita, na borda leste do Quadrilátero Ferrífero em Minas Gerais. A espécie foi originalmente registrada em cinco lagoas ou poças naturais em área de campo rupestre ferruginoso (canga), na região da Chapada de Canga e entorno. A partir de amostragens em campo e análise de coleção científica, são apresentados novos registros geográficos da espécie. Sphaenorhynchus canga foi registrado em sete novas localidades de corpos dágua lênticos, tanto naturais quanto antrópicos (pequenas represas), em áreas de campo rupestre ferruginoso e floresta estacional semidecidual antropizada. Como a descrição da espécie baseou-se apenas em machos, apresenta-se a morfometria das fêmeas analisadas, que se apresentaram maiores que machos. Seis localidades situam-se externamente aos limites da Chapada de Canga, mas S. canga continua sendo endêmico do Quadrilátero Ferrífero. São discutidos possíveis padrões de distribuição de $S$. canga e a influência da distribuição geográfica conhecida e da plasticidade ecológica sobre ameaças à espécie. 


\begin{abstract}
The tree frog Sphaenorhynchus canga was recently described, with restricted geographic distribution, on the eastern border of the Quadrilátero Ferrífero in Minas Gerais. The species was originally recorded in five lagoons or natural ponds in areas with ferruginous rupestrian grasslands (canga), in the Chapada de Canga region and surroundings. From field samplings and scientific collection analysis, we present new geographic records of the species. Sphaenorhynchus canga was recorded in seven new localities of lentic water bodies, both natural and anthropic (little dams), in areas witch ferruginous rupestrian grasslands and anthropogenic semideciduous seasonal forest. Since the description of the species was based only on males, we provide morphometrical data of females, which were larger than males. Six localities are outside the limits of Chapada de Canga, but $S$. canga remains endemic to the Quadrilátero Ferrifero. Possible distribution patterns of S. canga and the influence of the known geographic distribution and the ecological plasticity on threats to the species are discussed.
\end{abstract}

\title{
Palavras-chave
}

Anfíbios, Chapada de Canga, Quadrilátero Ferrífero, distribuição geográfica, endemismo, conservação

\section{Keywords}

Amphibians, Chapada de Canga, Quadrilátero Ferrífero, geographic distribution, endemism, conservation

Sphaenorhynchus canga Araujo-Vieira, Lacerda, Pezzuti, Leite, Assis \& Cruz, 2015 foi recentemente descrito com base em exemplares coletados na Chapada de Canga, no extremo norte do município de Mariana, porção leste do Quadrilátero Ferrífero em Minas Gerais, Brasil (Araujo-Vieira et al. 2015). A espécie foi observada em cinco lagoas e poças naturais, permanentes, semipermanentes ou temporárias, situadas sobre afloramentos rupestres em terrenos planos e rodeados por vegetação de campos rupestres (Araujo-Vieira et al. 2015).

Por meio do polígono convexo mínimo, Araujo-Vieira et al. (2015) calcularam uma extensão de ocorrência de $S$. canga de apenas $17,2 \mathrm{~km}^{2}$. Segundo Leite et al. (2017), S. canga possui distribuição extremamente restrita (exclusivamente na Chapada de Canga e entorno), em área sob forte pressão antrópica, estando exposto a diversas ameaças, tais como atividades de mineração, rodovias locais (risco de atropelamentos), queimadas e introdução de peixes exóticos, ressaltando que a espécie não tem registro em unidades de conservação. De acordo com Leite et al. (2017), esforços para detalhar a distribuição e buscar por novas populações da espécie são fundamentais e urgentes para assegurar a conservação de $S$. canga.

O Quadrilátero Ferrífero é uma área serrana com cerca de 7000 quilômetros quadrados, centralizado aproximadamente na latitude $20^{\circ} 15^{\prime} \mathrm{S}$ e longitude $43^{\circ} 30^{\prime} \mathrm{O}$ em Minas Gerais, Brasil (Dorr II 1969). A região é marcada por altos e robustos picos, longas cadeias de montanhas escarpadas, planaltos altos, alguns cânions profundos e vales abertos (Dorr II 1969). O Quadrilátero situa-se em uma zona de transição entre Cerrado e Mata Atlântica (Rizzini 1979; MMA, IBGE 2004), biomas reconhecidos como hotspots mundiais (Myers et al. 2000), e apresenta um diversificado mosaico de fitofisionomias (Kamino et al. 2008). Destacam-se os típicos cam- 
pos rupestres ferruginosos sobre os afloramentos de canga (Carmo e Jacobi 2013), especialmente a região da Chapada de Canga, na borda leste do Quadrilátero, um geossistema ferruginoso ainda com extensas áreas naturais e um singular complexo hídrico, contendo pelo menos 10 lagoas e poças naturais, de diversos tamanhos e regimes hídricos (Carmo e Kamino 2017; Leite et al. 2017).

Estudos sobre os anfíbios do Quadrilátero Ferrífero têm abordado composição faunística, taxonomia, distribuição geográfica e ecologia, especialmente nas últimas décadas (Leite et al. 2008; Nascimento et al. 2009). Na compilação realizada por Leite et al. (2008) foram listadas 63 espécies de anuros registradas em localidades do Quadrilátero Ferrífero (considerando a taxonomia atualizada), incluindo endemismos dessa região. No entanto, registros inéditos de anuros foram realizados posteriormente (como exemplo, Leite et al. 2017; Silveira et al. 2018). A elevada riqueza e a ocorrência de espécies endêmicas demonstram a relevância do Quadrilátero para a conservação de anuros. Atualmente, podem ser reconhecidos como endêmicos do Quadrilátero Ferrífero os anuros Physalaemus erythros Caramaschi, Feio \& Guimarães-Neto, 2003 e Hylodes uai Nascimento, Pombal Jr. \& Haddad, 2001, além de S. canga (Nascimento et al. 2001; Caramaschi et al. 2003; Eterovick e Barata 2006; Canelas e Bertoluci 2007; Leite et al. 2008; Baêta e Silva 2009; Leite e Guilherme 2009; Araujo-Vieira et al. 2015; Leite et al. 2017).

No presente trabalho são apresentados novos registros de $S$. canga em localidades adjacentes à Chapada de Canga, no Quadrilátero Ferrífero, Minas Gerais. Adicionalmente, como a descrição da espécie baseou-se apenas em machos, apresenta-se morfometria das fêmeas analisadas. Também são descritas algumas observações de história natural e comenta-se o nível de endemismo da espécie.

Os registros foram obtidos em uma ampla amostragem da herpetofauna realizada no período de março de 2016 a março de 2018, em 17 áreas no Quadrilátero Ferrífero, abrangendo os municípios de Mariana, Ouro Preto, Catas Altas, Santa Bárbara, Rio Acima, Itabirito, Nova Lima e Itabira, e incluindo nove Unidades de Conservação. Foi aplicado o método de busca ativa noturna em sítios reprodutivos (adaptado de Scott Jr. e Woodward 1994), sendo seis dias de amostragem em cada área (três na estação seca e três na estação chuvosa), totalizando um esforço de 552 horas-homem de buscas. Espécimes testemunhos foram coletados, preservados segundo a metodologia de rotina, que correspondeu à eutanásia com injeção de anestésico articaína, fixação com banho em solução de formaldeído 10\% por 24 horas e preservação em álcool 70\% (adaptado de McDiarmid 1994). Esses espécimes foram depositados nas coleções científica de anfíbios do Laboratório de Zoologia de Vertebrados, Universidade Federal de Ouro Preto (LZVUFOP) e do Centro de Coleções Taxonômicas da Universidade Federal de Minas Gerais (UFMG) (Tabela 1). As coletas foram autorizadas pelo Instituto Chico Mendes de Conservação da Biodiversidade (autorização n 21596-4) e pelo Instituto Estadual de Florestas - MG (autorização $n^{\circ}$ 028.059/2015/MG). Adicionalmente, foi localizado e analisado mais um exemplar na coleção LZVUFOP. A identificação taxonômica específica baseou-se na diagnose apresentada por Araujo-Vieira et 
Tabela 1. Dados dos registros de Sphaenorhynchus canga no município de Mariana (Minas Gerais, Brasil), incluindo os espécimes testemunhos coletados em campo ou localizados em coleção científica. LZVUFOP - Laboratório de Zoologia de Vertebrados, Universidade Federal de Ouro Preto; UFMG Centro de Coleções Taxonômicas da Universidade Federal de Minas Gerais.

\begin{tabular}{|c|c|c|c|c|c|c|c|}
\hline $\begin{array}{l}\text { Espécimes } \\
\text { testemunhos }\end{array}$ & Localidade & Latitude; Longitude & \begin{tabular}{|c|}
$\begin{array}{c}\text { Altitude } \\
(\mathrm{m})\end{array}$ \\
\end{tabular} & Ambiente & $\begin{array}{c}\text { Data de } \\
\text { coleta }\end{array}$ & Abundância & Registro \\
\hline $\begin{array}{l}\text { UFMG } \\
19753,19754 \\
\text { (machos) }\end{array}$ & $\begin{array}{c}\text { Distrito de Santa } \\
\text { Rita Durão, borda da } \\
\text { Chapada de Canga, } \\
\text { lagoa em afluente do } \\
\text { Córrego do Brumado }\end{array}$ & $20,1664^{\circ} \mathrm{S} ; 43,4332^{\circ} \mathrm{O}$ & 894 & $\begin{array}{l}\text { Lagoa natural em } \\
\text { transição campo } \\
\text { rupestre ferruginoso/ } \\
\text { floresta estacional } \\
\text { semidecidual } \\
\text { secundária }\end{array}$ & 29/III/2016 & 15 & $\begin{array}{c}\text { Coleta e } \\
\text { canto }\end{array}$ \\
\hline $\begin{array}{l}\text { UFMG } \\
19774,19775 \\
\text { (machos) }\end{array}$ & $\begin{array}{c}\text { Distrito de Santa Rita } \\
\text { Durão, represa da antiga } \\
\text { captação de água }\end{array}$ & $20,1760^{\circ} \mathrm{S} ; 43,4239^{\circ} \mathrm{O}$ & 898 & $\begin{array}{c}\text { Represa em floresta } \\
\text { estacional semidecidual } \\
\text { secundária }\end{array}$ & $11 / \mathrm{I} / 2017$ & 10 & $\begin{array}{c}\text { Coleta e } \\
\text { canto }\end{array}$ \\
\hline $\begin{array}{l}\text { LZVUFOP } \\
\text { 3393A, 3394A, } \\
\text { 3396A, 3397A } \\
\text { (machos); } \\
\text { LZVUFOP } \\
\text { 3392A (fêmea) }\end{array}$ & $\begin{array}{c}\text { Distrito de Santa } \\
\text { Rita Durão, Fazenda } \\
\text { Fábrica Nova Leste, } \\
\text { poças temporárias em } \\
\text { pequeno afloramento } \\
\text { de canga }\end{array}$ & $20,2028^{\circ} \mathrm{S} ; 43,3919^{\circ} \mathrm{O}$ & 848 & $\begin{array}{c}\text { Lagoa temporária } \\
\text { em campo rupestre } \\
\text { ferruginoso (canga) }\end{array}$ & $22 / \mathrm{XI} / 2016$ & 10 & $\begin{array}{c}\text { Coleta e } \\
\text { canto }\end{array}$ \\
\hline Sem coleta & $\begin{array}{l}\text { Distrito de Santa Rita } \\
\text { Durão, brejo em afluente } \\
\text { do Rio Piracicaba }\end{array}$ & $20,2090^{\circ} \mathrm{S} ; 43,3811^{\circ} \mathrm{O}$ & 803 & \begin{tabular}{|c|} 
Brejo antrópico \\
represado em capoeira \\
de floresta estacional \\
semidecidual e \\
eucaliptal \\
\end{tabular} & 23/XI/2016 & 1 & Canto \\
\hline $\begin{array}{l}\text { LZVUFOP } \\
3395 \mathrm{~A} \\
\text { (macho) }\end{array}$ & $\begin{array}{c}\text { Distrito de Santa Rita } \\
\text { Durão, Fazenda Fábrica } \\
\text { Nova Leste, represa no } \\
\text { Córrego Gambeta }\end{array}$ & $20,2164^{\circ} \mathrm{S} ; 43,3994^{\circ} \mathrm{O}$ & 815 & $\begin{array}{c}\text { Brejo de represa em } \\
\text { capoeira de floresta } \\
\text { estacional semidecidual } \\
\text { e eucaliptal }\end{array}$ & 23/XI/2016 & 3 & $\begin{array}{c}\text { Coleta e } \\
\text { canto }\end{array}$ \\
\hline $\begin{array}{l}\text { LZVUFOP } \\
3403 A \text { (fêmea) }\end{array}$ & $\begin{array}{l}\text { Distrito de Camargos, } \\
\text { represa no Córrego } \\
\text { Capitão }\end{array}$ & $20,2597^{\circ} \mathrm{S} ; 43,3761^{\circ} \mathrm{O}$ & 699 & $\begin{array}{c}\text { Represa com grande } \\
\text { brejo em pastagem } \\
\text { e floresta estacional } \\
\text { semidecidual } \\
\text { secundária }\end{array}$ & 23/III/2018 & 1 & Coleção \\
\hline Sem coleta & $\begin{array}{l}\text { Distrito de Bandeirantes, } \\
\text { represa em afluente do } \\
\text { Córrego Tambor }\end{array}$ & $20,3144^{\circ} \mathrm{S} ; 43,4106^{\circ} \mathrm{O}$ & 855 & $\begin{array}{c}\text { Pequena represa em } \\
\text { floresta estacional } \\
\text { semidecidual } \\
\text { secundária }\end{array}$ & $24 / \mathrm{III} / 2018$ & 2 & Canto \\
\hline
\end{tabular}

al. (2015). As principais medidas utilizadas por esses autores foram aferidas nos espécimes coletados, com uso de paquímetro analógico com precisão de 0,02 milímetro.

Sphaenorhynchus canga foi registrado em sete novas localidades de ocorrência, todas situadas no município de Mariana, correspondendo a sítios reprodutivos aquáticos. Nas amostragens em campo, cerca de 40 machos vocalizantes e uma fêmea de $S$. canga foram registrados em seis localidades, e na coleção LZVUFOP analisou-se uma fêmea procedente de mais uma localidade (Tabela 1, Fig. 1). A abundância local de machos variou de um a 15 indivíduos nas distintas localidades (Tabela 1), com destaque para a lagoa no afluente do Córrego do Brumado, onde se contabilizou o maior valor $(n=15)$. Espécimes testemunhos foram coletados em quatro das localidades de registro em campo (Tabela 1, Fig. 2).

Foram observados machos emitindo vocalização de anúncio nos meses de novembro, janeiro e março, o que indica um período reprodutivo mais estendido ao longo da estação chuvosa, do fim da primavera ao início do outono. Os machos 


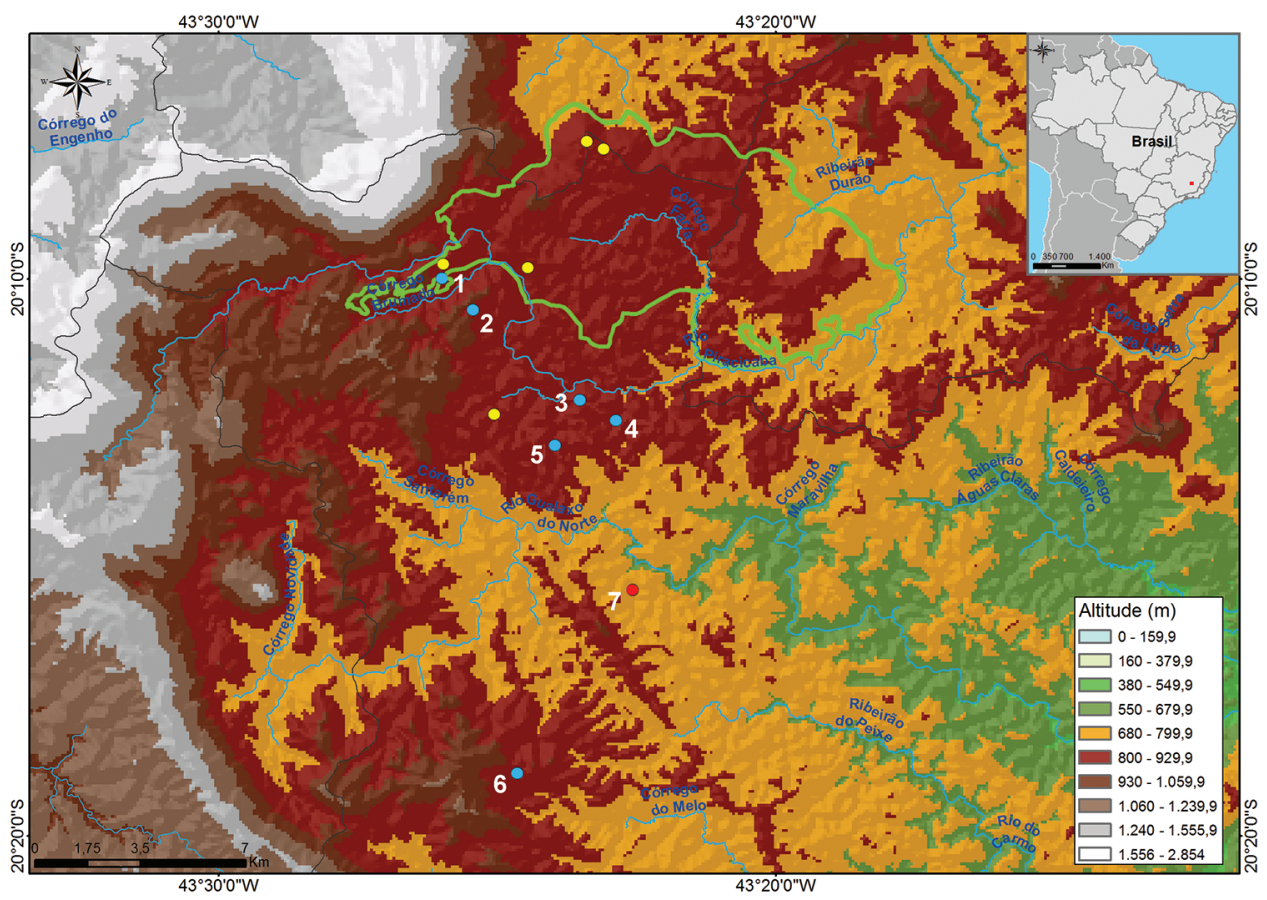

Figura 1. Distribuição geográfica de Sphaenorhynchus canga, em Mariana, Quadrilátero Ferrífero, Minas Gerais, Brasil, com a Chapada de Canga delimitada pela linha verde (base georreferenciada elaborada por Allaoua Saadi). Tipos de registros: novo registro da coleção LZVUFOP (ponto vermelho); novos registros de campo (pontos azuis); registros prévios (pontos amarelos; Araujo-Vieira et al. 2015).- 1. lagoa em afluente do Córrego do Brumado, 2. represa da antiga captação de água de Santa Rita Durão, 3. poças temporárias em pequeno afloramento de canga na Fazenda Fábrica Nova Leste, 4. brejo em afluente do Rio Piracicaba, 5. represa no Córrego Gambeta na Fazenda Fábrica Nova Leste, 6. represa em afluente do Córrego Tambor, 7. represa no Córrego Capitão.

estavam vocalizando sobre a vegetação aquática flutuante (salvínea), empoleirados na vegetação herbácea emergente da água (junco) ou empoleirados na vegetação arbustiva marginal, até uma altura de 1,5 metro do nível da água. Em dias chuvosos os machos vocalizavam no início da manhã, no fim da tarde e à noite, até cerca de meia noite, sendo que os coros intensificavam-se sob chuva fina.

Nove machos analisados (Tabela 1) foram identificados como S. canga por apresentarem os caracteres diagnósticos da espécie, descritos por Araujo-Vieira et al. (2015), sem variação significativa. Oito machos medidos apresentaram comprimento rostro-cloacal $(27,64-30,44 \mathrm{~mm})$ muito aproximado da amplitude descrita por Araujo-Vieira et al. (2015) (26,2-30,2 $\mathrm{mm})$.

As duas fêmeas analisadas (LZVUFOP 3392A e 3403A) apresentaram, respectivamente, as seguintes medidas ( $\mathrm{mm}$ ): comprimento rostro-cloacal: 30,16 e 30,96 ; comprimento da cabeça: 12,16 e 12,18; largura da cabeça: 10,42 e 10,40; distância internasal: 2,08 e 2,00; distância interorbital: 4,64 e 4,88; distância olho-narina: 2,82 e 3,00; diâmetro do olho: 2,60 e 2,90; comprimento da mão: 15,40 e 15,21; compri- 


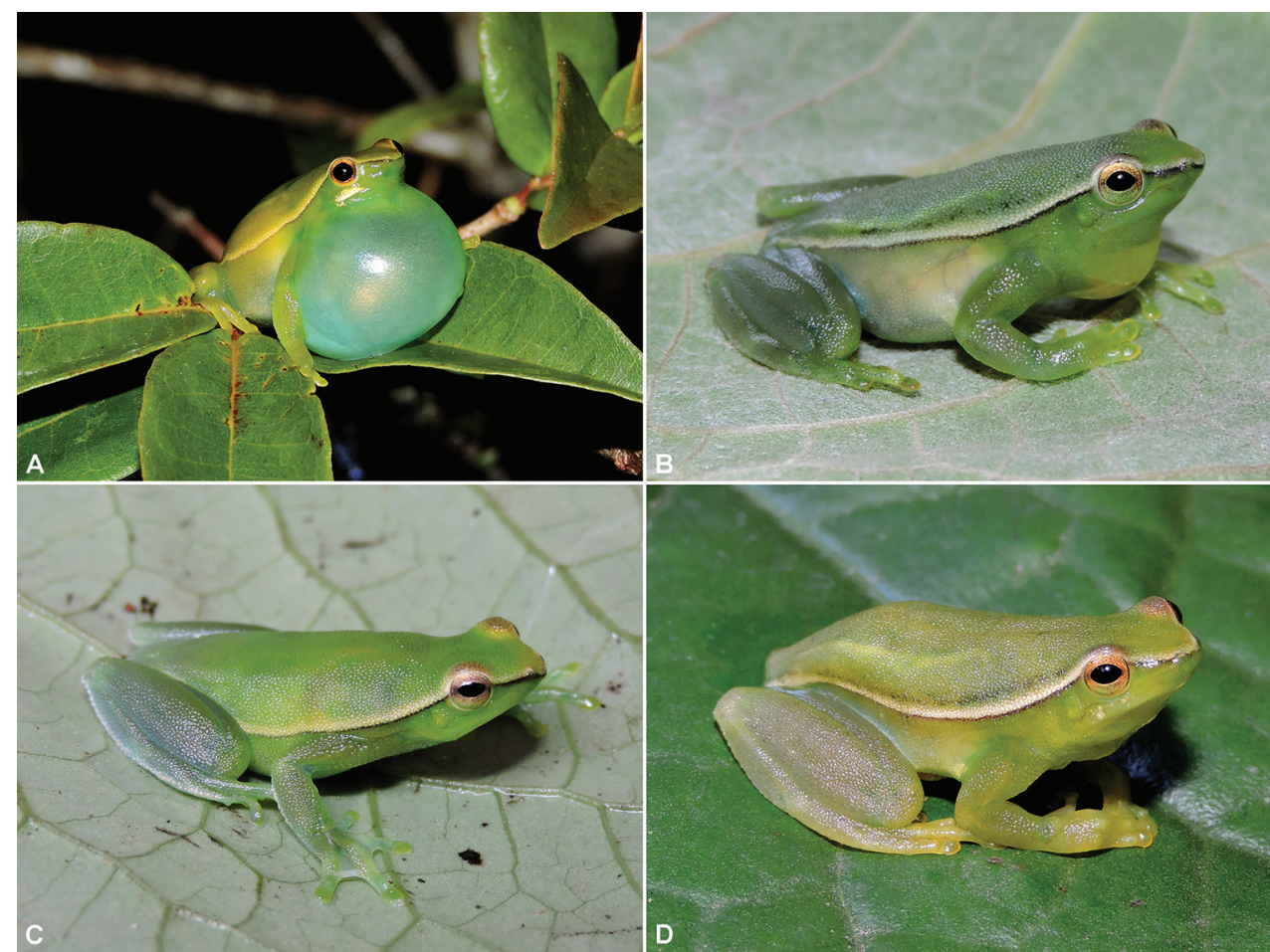

Figura 2. Espécimes de Sphaenorhynchus canga coletados nas novas localidades de registro, em Mariana, Minas Gerais, Brasil: A. LZVUFOP 3395A (macho), B. UFMG 19754 (macho), C. LZVUFOP 3392A (fêmea), D. UFMG 19774 (macho).

mento da coxa: 15,28 e 15,46; comprimento da tíbia: 15,16 e 15,34; comprimento do pé: 14,44 e 14,40; diâmetro do disco do terceiro dedo: 1,34 e 1,50; diâmetro do disco do quarto artelho: 1,40 e 1,40. As medidas das fêmeas foram maiores que aquelas dos machos apresentadas por Araujo-Vieira et al. (2015), com exceção da sobreposição parcial dos comprimentos rostro-cloacal, da coxa e da tíbia, da distância olho-narina e do diâmetro do olho. Cabe esclarecer que apenas essas duas fêmeas foram encontradas durante as amostragens ou depositadas em coleção. Em relação à fêmea observada em vida (LZVUFOP 3392A), a coloração foi semelhante à dos machos coletados, com exceção da região gular, a qual não exibiu a pigmentação escura presente em machos.

Duas localidades de registro corresponderam a ambientes aquáticos naturais: uma pequena lagoa perene, profunda (cerca de $3 \mathrm{~m}$ ) e situada em uma fenda, e um conjunto de poças temporárias e rasas (menos que $1 \mathrm{~m}$ ). A lagoa situa-se em área de transição entre campo rupestre ferruginoso e floresta estacional semidecidual, localizada na borda sudoeste da Chapada de Canga (Fig. 3A). Esse corpo d’água, primariamente natural, pode ter sofrido aprofundamento decorrente de histórica atividade garimpeira. As poças temporárias localizam-se em uma pequena mancha de campo rupestre ferruginoso (canga), disjunta da Chapada de Canga (Fig. 3B). Demais lo- 
calidades corresponderam a represas e brejos antrópicos, todos perenes, situados no interior ou na borda de remanescentes de floresta estacional semidecidual com distintos estágios de conservação, incluindo uma represa circundada por pastagem e floresta (Fig. 3C, D). Todos os sítios de registro corresponderam a coleções d’água lênticas e apresentavam macrófitas aquáticas, especialmente junco e salvínea.

Cinco das novas localidades de registro estão situadas entre os rios Piracicaba e Gualaxo do Norte, ao passo que duas situam-se ao sul do segundo rio. Apenas a localidade de registro mais setentrional (lagoa natural) está situada na Chapada de Canga, sendo que as outras seis localizam-se externamente aos limites da Chapada, na borda oriental do Quadrilátero Ferrífero. A represa no afluente do Córrego Tambor, onde foi obtido o registro mais meridional, pertence à microbacia do Rio do Carmo. Esses registros ampliam a distribuição geográfica conhecida de $S$. canga em $12 \mathrm{~km}$ ao sul da localidade de registro prévio mais próximo, nas proximidades de Santa Rita Durão (Araujo-Vieira et al. 2015). Embora seja uma pequena distância, a ampliação é significativa para uma espécie com distribuição previamente tão restrita.

Com base nos novos registros, a distribuição geográfica de S. canga é redefinida para a Chapada de Canga e região ao sul desta, nas cabeceiras das bacias dos rios Piracicaba, Gualaxo do Norte e Carmo, incluindo manchas disjuntas de campo rupestre sobre canga com poças temporárias e áreas de floresta estacional semidecidual antropizada com represas e brejos antrópicos. A espécie continua sendo reconhecida como endêmica do Quadrilátero Ferrífero. Embora Araujo-Vieira et al. (2015) tenham considerado que $S$. canga era conhecido apenas na Chapada de Canga, sua ocorrência externa a essa área já havia sido evidenciada pelos autores, uma vez que uma das localidades mencionadas corresponde a um corpo d'água lêntico situada ao sul de Santa Rita Durão, a cerca de $4 \mathrm{~km}$ ao sul da Chapada, em uma área bastante antropizada.

Os novos registros também evidenciam que $S$. canga exibe uma maior plasticidade ecológica, ocorrendo em formações de campo rupestre ferruginoso, floresta estacional semidecidual secundária e eucaliptal com regeneração florestal, estando adaptado a reproduzir-se em corpos d'água lênticos antrópicos, tais como represas e brejos, além das lagoas e poças naturais.

Esses novos dados sugerem dois possíveis padrões de distribuição geográfica. Em um primeiro cenário, S. canga seria originalmente restrito à Chapada de Canga, reproduzindo-se em lagoas e poças naturais, e secundariamente ampliou sua distribuição para áreas de floresta antropizada adjacentes, onde se adaptou para reproduzir-se em brejos e represas antrópicos. Outro cenário seria que $S$. canga apresente distribuição na região de Mata Atlântica situada a leste do Quadrilátero Ferrífero, exibindo limite ocidental da área de ocorrência na Chapada de Canga, não alcançando serras mais elevadas do Quadrilátero, e atualmente se reproduzindo em ambientes lênticos naturais e antrópicos. Esse segundo padrão explicaria a ausência de registros de $S$. canga nos campos rupestres da Serra do Caraça, na adjacência oeste da Chapada de Canga, como comentado por Araujo-Vieira et al. 


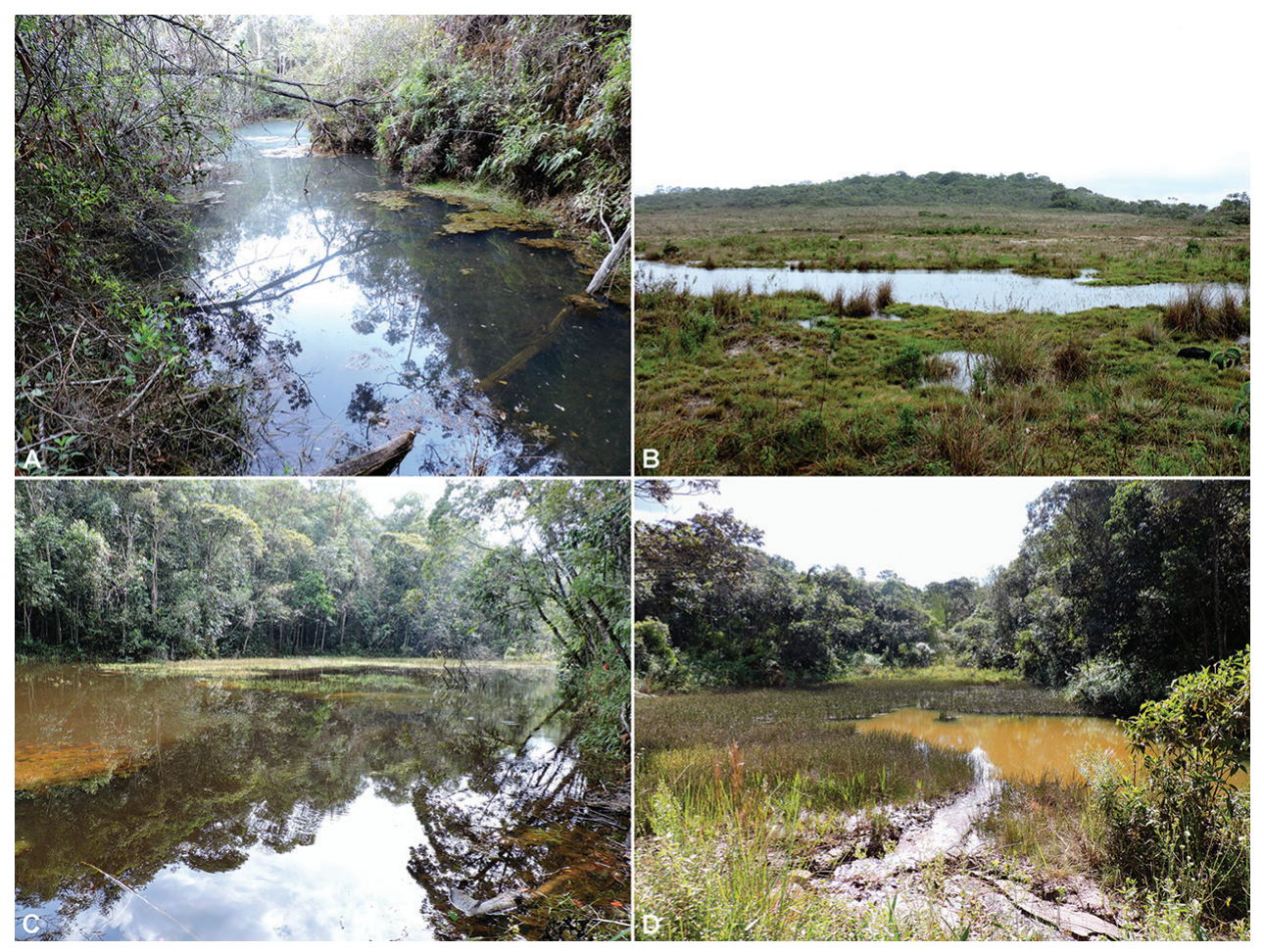

Figura 3. Habitats de coleta de Sphaenorhynchus canga em Mariana, Quadrilátero Ferrífero, Minas Gerais, Brasil: A. lagoa em área de transição entre campo rupestre ferruginoso e floresta estacional semidecidual, B. poça temporária em campo rupestre ferruginoso, C-D. pequenas represas em floresta estacional semidecidual.

(2015). Cabe acrescentar que uma das áreas amostrais do presente estudo foi um planalto de campo rupestre com lagoas e poças naturais temporárias na Serra do Caraça $\left(20,1092^{\circ} \mathrm{S} ; 43,4905^{\circ} \mathrm{O}, 1254 \mathrm{~m}\right.$ elev.), onde não houve registros de $S$. canga. Mais esforços amostrais na região a leste do Quadrilátero, associados a estudos de filogeografia, focando os componentes espaciais e estruturais das populações (Beheregaray 2008), poderiam auxiliar na elucidação do padrão de distribuição da espécie.

O caráter de distribuição restrita a uma área fortemente antropizada (Chapada de Canga) e de restrição a habitat (campo rupestre ferruginoso com lagoas e poças naturais) significaria que toda a população de $S$. canga poderia estar exposta às ameaças locais, descritas por Leite et al. (2017). No entanto, a ampliação da distribuição geográfica conhecida e a constatação de uma maior plasticidade ecológica da espécie indicam menor magnitude das ameaças antrópicas existentes na Chapada de Canga sobre S. canga. Ainda assim há necessidade de uma avaliação do estado de conservação da espécie, o qual permanece indefinido, pois os novos locais de registro correspondem a áreas antropizadas e não há ocorrências conhecidas de S. canga em áreas protegidas, tais como Unidades de Conservação. 


\section{Agradecimentos}

Agradecemos à companhia Vale S. A., pelo suporte financeiro e autorização de publicação dos dados levantados em projetos ambientais; à empresa Amplo Engenharia e Gestão de Projetos, pelo suporte logístico e técnico; a Maria Rita S. Pires, pela autorização de consulta à coleção de anfíbios da Universidade Federal de Ouro Preto; a José Janderson F. Rocha e Darllen Felipe S. Dias, pelo apoio nas atividades de campo; a Allaoua Saadi, por ceder a base georreferenciada da Chapada de Canga; a Alessandro C. Pereira, pelo auxílio na confecção do mapa; e aos revisores anônimos, pelas correções e sugestões ao manuscrito.

\section{Referências}

Araujo-Vieira K, Lacerda JVA, Pezzuti TL, Leite FSF, Assis CL, Cruz CAG (2015) A new species of Hatchet-faced Treefrog Sphaenorhynchus Tschudi (Anura: Hylidae) from Quadrilátero Ferrífero, Minas Gerais, southeastern Brazil. Zootaxa 4059(1): 96-114. https:// doi.org/10.11646/zootaxa.4059.1.5

Baêta D, Silva DH (2009) Amphibia, Anura, Leiuperidae, Physalaemus erythros Caramaschi, Feio and Guimarães-Neto, 2003: Distribution extension. Check List 5(4): 81814. https://doi.org/10.15560/5.4.812

Beheregaray LB (2008) Twenty years of phylogeography: The state of the field and the challenges for the Southern Hemisphere. Molecular Ecology 17: 3754-3774. https://doi. org/10.1111/j.1365-294X.2008.03857.x

Canelas MAS, Bertoluci J (2007) Anurans of the Serra do Caraça, southeastern Brazil: Species composition and phenological patterns of calling activity. Iheringia. Série Zoologia 97(1): 21-26. https://doi.org/10.1590/S0073-47212007000100004

Caramaschi U, Feio RN, Guimarães Neto AS (2003) A new, brightly colored species of Physalaemus (Anura: Leptodactylidae) from Minas Gerais, Southeastern Brazil. Herpetologica 59(4): 521-526. https://doi.org/10.1655/02-102

Carmo FF, Jacobi CM (2013) A vegetação de canga no Quadrilátero Ferrífero, Minas Gerais: Caracterização e contexto fitogeográfico. Rodriguésia 64(3): 527-541. https://doi. org/10.1590/S2175-78602013000300005

Carmo FF, Kamino LHY (2017) Chapada de Canga: uma introdução. In: Kamini LHY, Carmo FF (Orgs) Chapada de Canga: Patrimônio Natural e Cultural de Relevante Interesse Para a Conservação (3i Ed.). Belo Horizonte, 11-24.

Dorr II JVN (1969) Physiographic, stratigraphic and structural development of the Quadrilatero Ferrifero Minas Gerais, Brazil. Geological Survey Professional Paper 641(A): I-V+A1-A110. https://doi.org/10.3133/pp641A

Eterovick PC, Barata IM (2006) Distribution of tadpoles within and among Brazilian streams: The influence of predators, habitat size and heterogeneity. Herpetologica 62(4): 365-377. https://doi.org/10.1655/0018-0831(2006)62[365:DOTWAA]2.0.CO;2

Kamino LHY, Oliveira-Filho AT, Stehmann JR (2008) Relações florísticas entre as fitofisionomias florestais da Cadeia do Espinhaço, Brasil. Megadiversidade 4(1-2): 39-49. 
Leite FSF, Guilherme MBF (2009) Anfíbios e Répteis/Herpetofauna. Anglogold Ashanti. Biodiversidade da Mata Samuel de Paula. AngloGold Ashanti, Belo Horizonte, 165-186. Leite FSF, Junca FA, Eterovick PC (2008) Status do conhecimento, endemismo e conservação de anfíbios anuros da Cadeia do Espinhaço, Brasil. Megadiversidade 4(1-2): 158-176.

Leite FSF, Mascarenhas L, Eterovick PC (2017) Diversidade de anfíbios associada às lagoas naturais da Chapada de Canga e sua importância para a conservação da anurofauna dos geossistemas ferruginosos. In: Kamini LHY, Carmo FF (Orgs) Chapada de Canga: Patrimônio Natural e Cultural de Relevante Interesse Para a Conservação (3i Ed.). Belo Horizonte, 265-284.

McDiarmid RW (1994) Preparing amphibians as scientific specimens. In: Heyer WR, Donnelly MA, Mcdiarmind RW, Hayek LC, Foster MS (Eds) Measuring and Monitoring Biological Diversity: standard methods for Amphibians. Smithsonian Institution Press, Washington, 289-297.

MMA, IBGE (2004) Mapa de biomas do Brasil: primeira apresentação. Escala 1:5.000.000. Instituto Brasileiro de Geografia e Estatística, [S.l.], 1 mapa.

Myers N, Mittermeier RA, Mittermeier CG, Fonseca GAB, Kent J (2000) Biodiversity hotspots for conservation priorities. Nature 430(6772): 853-858. https://doi. org/10.1038/35002501

Nascimento LB, Pombal Jr JP, Haddad CFB (2001) A new frog of the genus Hylodes (Amphibia: Leptodactylidae) from Minas Gerais, Brazil. Journal of Zoology 254(4): 421428. https://doi.org/10.1017/S0952836901000917

Nascimento LB, Leite FSF, Eterovick PC, Feio RN (2009) Anfíbios. In: Drummond GM, Martins CS, Greco MB, Vieira F (Eds) Biota Minas: diagnóstico do conhecimento sobre a biodiversidade no Estado de Minas Gerais - subsídio ao Programa Biota Minas. Fundação Biodiversitas, Belo Horizonte, 221-248.

Rizzini CT (1979) Tratado de Fitogeografia do Brasil. Editora Âmbito Cultural, Rio de Janeiro, $374 \mathrm{pp}$.

Scott Jr NJ, Woodward BD (1994) Surveys at breedings sites. In: Heyer WR, Donnely MA, McDiarmid RW, Hayek LAC, Foster MS (Eds) Measuring and Monitoring Biological Diversity: Standards Methods for Amphibians. Smithsonian Institution Press, Washington, 118-125.

Silveira AL, Ribeiro LSVB, Dornas TT, Fernandes TN (2018) Primeiro registro de Leptodactylus cupreus (Anura, Leptodactylidae) no Quadrilátero Ferrífero em Minas Gerais, Brasil. Revista Brasileira de Biociências 16(2): 47-52. 